\title{
C-Banding Karyotype and Molecular Characterization on Cumin, Caraway and Coriander
}

Ibrahim M.A. ${ }^{1 *}$, Bekhit $\mathbf{M}^{2}$, Neveen Hassan ${ }^{1}$, Refaat $\mathbf{M}^{2}$ and El-Akkad T21National Gene Bank, Agriculture

Research Center, Giza, Egypt2Faculty of Agriculture, Banha University, Mushtohor, Banha, Egypt

\begin{abstract}
Our goal for this study to characterize three species germplasm of family Apiaceae, namely (cumin, caraway and coriander), to make a chromosome characterization and molecular fingerprint for the mentioned species. Results performed on Karyomorphological showed that; Cuminum cyminum L. (cumin: 2n=14), Carum carvi (caraway: $2 \mathrm{n}=20$ ) and Coriandrum sativum (coriander: $2 \mathrm{n}=22$ ). The total Chromatin Relative Length percentage ( $\mathrm{RL} \%$ ) showed cumin $\pm 10.69 \mu \mathrm{m} \pm 19.70 \mu \mathrm{m}$, caraway $\pm 7.30 \mu \mathrm{m} \pm 13.40 \mu \mathrm{m}$ and coriander $\pm 5.58 \mu \mathrm{m} \pm 12.07$ $\mu \mathrm{m}$. Satellites in all the cases were associated to short arms. The molecular characterization for the three species (caraway, cumin, and coriander) was conducted using 5 AFLP combinations and 15 anchored-ISSR primers. The total amplified bands were 330 (162 ISSR+168 AFLP), with an average 83.75\% (89.5 ISSR+78 AFLP) per primer. The combined dendrogram based on both AFLP and SSR markers for the three accessions was divided into 2 main clusters; the first cluster has 2 accessions (caraway and cumin) with $60 \%$ similarity, while coriander falls in a distinct cluster.

*Corresponding author: Muhammad A Ibrahim, Assistant Researcher, National Gene Bank Agricultural Research Center, Giza, Egypt, Tel: +20235693359; E-mail: maibrahim30@icloud.comReceived May 09, 2019; Accepted June 05, 2019; Published June 12, 2019

Citation: Ibrahim MA, Bekhit M, Hassan N, Refaat M, El-Akkad T (2019) C-Banding Karyotype and Molecular Characterization on Cumin, Caraway and Coriander. Mol Biol 8: 229. Copyright: () 2019 Ibrahim MA, et al. This is an open-access article distributed under the terms of the Creative Commons Attribution License, which permits unrestricted use, distribution, and reproduction in any medium, provided the original author and source are credited.
\end{abstract}

Keywords: Karyotype; Cytogenetic; Cytology; C-banding; Chromosome; Cumin; Caraway; Coriander; AFLP; ISSR molecular marker

(PDF) C-Banding Karyotype and Molecular Characterization of Cumin, Caraway and Coriander. Available from: https://www.researchgate.net/publication/334386491_C-

Banding_Karyotype and_Molecular_Characterization_of_Cumin_Caraway and_Coriander [accessed Dec 04 2019]. 